\title{
Further observations on retromolar fibreoptic orotracheal intubation in patients with severe trismus
}

\author{
Fu S. Xue, MD • Nong He, MD • Xu Liao, MD • \\ Xiu Z. Xu, MD • Jian H. Liu, MD
}

Received: 4 May 2011/ Accepted: 2 June 2011/Published online: 11 June 2011

(C) Canadian Anesthesiologists' Society 2011

\section{To the Editor,}

We congratulate Truong et al. ${ }^{1}$ on their successful airway management using retromolar fibreoptic orotracheal intubation in a patient with severe trismus undergoing nasal surgery. We too have employed this technique in three adult patients during the past five years. The first case involved a 52-yr-old woman who suffered from a severely limited mouth opening (interincisor distance $=7 \mathrm{~mm}$ ) due to previous radiotherapy for oral cancer. On this admission, she underwent nasal metastatic tumour excision and temporomandibular joint arthroplasty. The second case involved a 21-yr-old male with chronic temporomandibular joint ankylosis (interincisor distance $=5 \mathrm{~mm}$ ), mandibular hypoplasia, and left nasal passage stenosis. He was scheduled for temporomandibular joint arthroplasty and surgery of the left nasal passage. The third case involved a 32-yr-old male with decerebrate rigidity secondary to brain trauma. He had severe trismus (interincisor distance $=0 \mathrm{~mm}$ ), a basal skull fracture, and cerebrospinal fluid rhinorrhea, and he required orotracheal intubation for airway management because his legally responsible relative refused tracheotomy. In all three cases, retromolar fibreoptic orotracheal intubation was an effective choice to secure an airway for patients with concomitant severe

Fu Shan Xue and Nong He-contributed equally to this work.

F. S. Xue, MD $(\varangle) \cdot$ X. Liao, MD · J. H. Liu, MD

Plastic Surgery Hospital, Chinese Academy of Medical Sciences and Peking Union Medical College, Beijing,

People's Republic of China

e-mail: fruitxue@yahoo.com.cn

N. He, MD - X. Z. Xu, MD

Peking University Shougang Hospital,

Beijing, People's Republic of China trismus and contraindications to nasotracheal intubation. We offer several observations from our experience to facilitate use of retromolar fibreoptic intubation:

(1) When the retromolar space is used for placement of the endotracheal tube (ETT) during maxillofacial surgery, either a regular ETT or a flexible wirereinforced tube can be used. ${ }^{2}$ When performing retromolar fibreoptic intubation in patients with a severely limited mouth opening, however, a wirereinforced tube may be more helpful than the more rigid regular ETT for tube insertion over the fibreoptic bronchoscope (FOB). In our second case, when a 7.0-mm polyvinyl chloride ETT was advanced over a FOB with an outer diameter of $4.1 \mathrm{~mm}$ via the left retromolar space, repeated obstruction occurred at the level of the larynx. After inserting another FOB into the upper airway through the right retromolar space, fibroscopy showed that the ETT tip was entering into the epiglottic vallecula due to the natural curvature of the ETT. Furthermore, routine corrective measures, such as rotation of the ETT, adjustment of the patient's head position, and external laryngeal manipulations, ${ }^{3}$ were unable to overcome this difficulty. Subsequently, reintubation with a size $7.0 \mathrm{~mm}$ wirereinforced tube was successful on first attempt.

(2) Due to developmental differences of the third molars, the retromolar spaces located between the back of the third molar and the anterior edge of the ascending ramus of the mandible may differ between the two sides. $^{4,5}$ This implies that one retromolar space may be more suitable than the other for passage of an ETT. Before tracheal intubation, we recommend evaluating the potential of both retromolar spaces to accommodate the tube by attempting to pass a preselected ETT. 
Also, a larger retromolar space should be selected for fibreoptic intubation.

(3) The experience from maxillofacial surgeons suggests that smaller ETTs fit better into the retromolar space. For example, $6.5 \mathrm{~mm}$ and $7.0 \mathrm{~mm}$ ETTs are preferred sizes for female and male adult patients, respectively. ${ }^{2}$ Furthermore, to facilitate ETT passage and prevent cuff damage by the last molars, we emphasize the importance of adequate tube lubrication and active cuff deflation prior to tube insertion.

(4) Considering the risk of a "cannot intubate-cannot ventilate" situation after induction of anesthesia and administration of neuromuscular blocking drugs for these cases, we performed awake fibreoptic intubation after sedation with midazolam and opioids, and we topicalized the airway with $2 \%$ lidocaine by translaryngeal injection and/or a spray-as-you-go technique via the FOB. For better exposure during fibroscopy and intubation via the retromolar space, an assistant pulled the corner of the patient's mouth using a surgical retractor. Also, the patients breathed 100\% oxygen using a nasal catheter.

(5) In a patient who has a limited mouth opening, if possible (for example our first case), the FOB can be inserted by the midline approach to make fibroscopy easier. After placement of the FOB tip into the midtracheal position, the FOB is pushed into the retromolar space, and then the ETT is advanced over it into the trachea with a slight rotating motion. To protect the FOB from being bitten by the awake patient during fibroscopy, an anti-biting device, such as an infant oral airway or a small gauze bite block, should be placed between the lateral incisors.

(6) Since the relationship between the external tube markings and the location of the tube tip in the trachea is not firmly established during orotracheal intubation via the retromolar space, the operator must determine that the tube tip is positioned $3-4 \mathrm{~cm}$ above the carina by direct visualization through the FOB before withdrawing the FOB from the tube.

Competing interests None declared.

\section{References}

1. Truong A, Truong DT. Retromolar fibreoptic orotracheal intubation in a patient with severe trismus undergoing nasal surgery. Can J Anesth 2011; 58: 460-3.

2. Lee SS, Huang $S H, W u S H$, et al. A review of intraoperative airway management for midface facial bone fracture patients. Ann Plast Surg 2009; 63: 162-6.

3. Asai $T$, Shingu $K$. Difficulty in advancing a tracheal tube over a fibreoptic bronchoscope: incidence, causes and solutions. $\mathrm{Br} \mathrm{J}$ Anaesth 2004; 92: 870-81.

4. Uthman AT. Retromolar space analysis in relation to selected linear and angular measurements for an Iraqi sample. Oral Surg Oral Med Oral Pathol Oral Radiol Endod 2007; 104: e76-82.

5. Arora $S$, Rattan $V$, Bhardwaj $N$. An evaluation of the retromolar space for oral tracheal tube placement for maxillofacial surgery in children. Anesth Analg 2006; 103: 1122-5. 